\title{
Carboplatin-etoposide combination chemotherapy in metastatic castration-resistant prostate cancer: A retrospective study
}

\author{
MATTHIEU CAUBET ${ }^{1}$, ERION DOBI ${ }^{2,3}$, ASTRID POZET $^{4}$, HAMADI ALMOTLAK $^{2,5}$, \\ PHILIPPE MONTCUQUET ${ }^{2,6}$, TRISTAN MAURINA ${ }^{2,3}$, GUILLAUME MOUILLET $^{2,3}$, \\ THIERRY N'GUYEN ${ }^{2}$, ULRICH STEIN ${ }^{2,6}$, ANTOINE THIERY-VUILLEMIN ${ }^{2}$ and FREDERIC FITENI ${ }^{2,4}$ \\ ${ }^{1}$ Department of Radiotherapy, ${ }^{2}$ Department of Medical Oncology, University Hospital of Besançon, \\ 25030 Besançon; ${ }^{3}$ Department of Medical Oncology, Hospital of Montbéliard, 25200 Montbéliard; \\ ${ }^{4}$ Methodology and Quality of Life in Oncology Unit, University Hospital of Besançon, 25030 Besançon; \\ ${ }^{5}$ Department of Medical Oncology, Hospital of Lons-le-Saunier, 39000 Lons-le-Saunier; \\ ${ }^{6}$ Department of Medical Oncology, Vesoul Hospital, 70000 Vesoul, France
}

Received May 18, 2015; Accepted June 22, 2015

DOI: $10.3892 /$ mco.2015.628

\begin{abstract}
The combination of cisplatin or carboplatin and etoposide is the standard treatment for certain poorly differentiated neuroendocrine cancers, such as small-cell lung cancer. The aim of this study was to assess the efficacy and tolerability of the carboplatin-etoposide regimen in metastatic castration-resistant prostate cancer (mCRPC). A total of 27 patients treated by carboplatin [area under the curve (AUC)=5] and etoposide $\left(100 \mathrm{mg} / \mathrm{m}^{2}\right.$ intravenous infusion on days $1-3$ or $75 \mathrm{mg}$ orally/day for 10 days) for mCRPC were included for analysis. The median progression-free survival was 3.3 months [95\% confidence interval (CI): 1.9-4.2] and the median overall survival (OS) was 8.1 months (95\% CI: 4.06-12.36). The main grade 3-4 toxicities were haematological, namely anemia $(33.3 \%)$, neutropenia $(25.9 \%)$ and thrombocytopenia $(22.2 \%)$, whereas the most common non-hematological toxicity was asthenia (22.2\%). The efficacy, compliance and safety profile were generally similar between the oral and intravenous etoposide groups. Pretreated patients with mCRPC may benefit from the carboplatin-etoposide regimen in terms of OS. The toxicities were acceptable, without reported treatment-related mortality. Therefore, the oral etoposide regimen may be an viable alternative for improving the quality of life of the patients. However, this regimen requires further prospective investigation to confirm its efficacy.
\end{abstract}

Correspondence to: Dr Frédéric Fiteni, Methodology and Quality of Life in Oncology Unit, University Hospital of Besançon, 3 Boulevard Alexander Fleming, 25030 Besançon, France

E-mail: fredericfiteni@gmail.com

Key words: carboplatin, etoposide, prostate cancer, neuroendocrine cancer

\section{Introduction}

Prostate cancer is the second most frequently diagnosed type of cancer and the sixth leading cause of cancer-related mortality in men, accounting for $14 \%(903,500)$ of total new cancer cases and $6 \%(258,400)$ of total cancer deaths in men in 2008 (1). The treatment paradigm for metastatic castration-resistant prostate cancer (mCRPC) is changing rapidly and numerous treatments are available. In heavily preteated patients, neuroendocrine transdifferentiation may be a mechanism of treatment escape (2-5). The combination of cisplatin or carboplatin and etoposide is the standard treatment for certain poorly differentiated neuroendocrine cancers, such as small-cell lung cancer (6). Of note, the combination of carboplatin and etoposide has provided encouraging results in $\mathrm{mCRPC}$. In a phase II trial by Loriot et al (7) assessing the combination of carboplatin [area under the curve (AUC) $=5$ on day 1] and etoposide (80 mg/m²/day, intravenous infusion on days 1-3) following first-line treatment with docetaxel, the response rate was $23 \%$, the median progression-free survival (PFS) was 2.1 months (range, 0.6-9.6 months) and the median overall survival (OS) was 19 months (range, 2.1-27.7 months). A phase II trial by Fléchon et al (8) investigating patients with anaplastic progressive $\mathrm{mCRPC}$ assessed carboplatin (AUC=4 on day 1) and etoposide $\left(100 \mathrm{mg} / \mathrm{m}^{2} /\right.$ day as an intravenous infusion on days 1-3). The response rate was $8.9 \%$, the PFS was 2.9 months [95\% confidence interval (CI): 1.7-3.5] and the median OS was 9.6 months (95\% CI: 8.7-12.7).

Prolonged fractionated oral administration of etoposide may provide a theoretical advantage in terms of toxicity over intravenous administration of a bolus dose. A phase I trial by Thiery-Vuillemin et al (9) evaluating the combination of carboplatin (AUC $=5$ on day 1 ) and oral etoposide ( $25 \mathrm{mg}, 3$ times daily) in 19 patients with varied solid tumors, 3 of whom had prostate cancer, reported an acceptable toxicity profile.

In the University Hospital of Besançon, administration of carboplatin-etoposide, orally or intravenously, has been used for heavily pretreated patients with mCRPC. This 
retrospective study aimed to assess the efficacy and tolerability of this regimen and compare the efficacy and tolerability of carboplatin plus oral etoposide vs. carboplatin plus intravenous etoposide.

\section{Patients and methods}

Study population. The Bonne Pratiques de Chimiothérapie $\left(\mathrm{BPC}^{\circledR}\right)$ software, which is a computer software for chemotherapy prescription from the medical office to the centralized pharmaceutical unit in charge of antineoplastic drug preparations, has been routinely used since 2001 . The BPC ${ }^{\circledR}$ software prospectively registers the type of disease, the physician in charge, the date of treatment cycles, the type of regimen, the possible dose adjustments, the cause of interruption and the treatment delay. Through this database, all consecutive patients with metastatic prostate cancer treated by carboplatin $(\mathrm{AUC}=5)$ and etoposide $\left(100 \mathrm{mg} / \mathrm{m}^{2}\right.$ intravenous infusion on days 1-3 every 3 weeks, or $75 \mathrm{mg}$ orally administered daily for 10 days every 4 weeks) in the Federative Regional Cancer Institute of Franche-Comté were identified.

The Doubs Cancer Registry provided information on patient outcomes, patient and tumor characteristics and survival data. To complete the database, a retrospective search through the medical charts was conducted to collect information on the site of metastatic lesions, performance status (PS), lines of anticancer treatment, adverse events, treatment response and date of progression. The biological status was assessed after each cycle and tumor response was assessed at 3 and 6 months after treatment initiation. This database has been approved by the National Commission on Informatics and Liberties (no. 2012-412 of 22/11/2012). The protocol was approved by the Central Ethics Committee (Comité de Protection des Personnes Est-II).

Statistical analysis. The primary objective was the assessment of the efficacy of the carboplatin-etoposide regimen in terms of OS. The secondary endpoints were PFS, treatment response, compliance and safety of the carboplatin-etoposide regimen. In addition, carboplatin plus oral etoposide and carboplatin plus intravenous etoposide were compared in terms of PFS, OS, compliance (measured by dose intensity of oral etoposide and intravenous etoposide) and safety.

The PFS was determined from the date of initiation of carboplatin-etoposide treatment to disease progression or death from any cause. Progression was defined as the earliest indication of radiological progression according to the Response Evaluation Criteria in Solid Tumours (RECIST) 1.1 (10), or biological progression, according to prostate-specific antigen (PSA) levels as determined by the criteria of the Prostate Cancer Clinical Trials Working Group (11). Patients who remained alive without disease progression were censored at the last follow-up. The OS was estimated from the time of the carboplatin-etoposide initiation to death from any cause. Patients who remained alive were censored at the last follow-up. The response rate was estimated according to RECIST 1.1.

PFS and OS were estimated using the Kaplan-Meier method and described as median and 95\% CI. Survival curves were compared using the log-rank test. A univariate Cox regression analysis for OS were performed to estimate hazard ratio (HR) with its $95 \% \mathrm{CI}$. The factors investigated as potentially asso- ciated with OS were analyzed using the Cox proportional hazard model and included age (>63 vs. <63 years), type of tumor (adenocarcinoma vs. mixed tumor with neuroendocrine component), PS (0/1 vs. 2/3), metastatic site (bone alone vs. bone \pm visceral metastases), chemotherapy regimen (etoposide administered orally or intravenously). The median follow-up was estimated using the reverse Kaplan-Meier method.

Overall response rate (ORR) was defined as the sum of complete response and partial response. Dose intensity was defined as the amount of oral or intravenous etoposide administered during the entire treatment. Toxicity events were reported according to the National Cancer Institute's Common Toxicity Criteria v4.0 (http://evs.nci.nih.gov/ftp1/ CTCAE/CTCAE_4.03_2010-06-14_QuickReference_8.5x11. pdf). Continuous variables were described as median and qualitative variables were described as frequencies and percentages. A P-value of $<0.05$ was considered to be statistically significant. All the statistical analyses were performed using SAS ${ }^{\circledR} 9.3$ software (SAS Institute Inc., Cary, NC, USA) and R-2.15.3 software (http://www.r-project.org/).

\section{Results}

Patient characteristics. Between 2006 and 2013 a total of 27 patients with mCRPC were treated at the Department of Oncology, University Hospital of Besançon (Besançon, France) with a carboplatine-etoposide regimen. Of the 27 patients, $17(63 \%)$ received oral etoposide and $10(37 \%)$ intravenous etoposide.

The baseline characteristics of the patients are presented in Table I. The mean age was 63.4 years (range, $49-75$ years), and the median Gleason score was 8 . The majority of the patients $(85 \%)$ exhibited a good Eastern Cooperative Oncology Group (ECOG) PS at diagnosis (0-1). A total of 25 patients $(92.6 \%)$ had bone metastases, 20 patients $(74 \%)$ presented with visceral \pm bone metastases and 7 patients presented with bone metastases without visceral metastases. The carboplatin-etoposide regimen was commonly administered as second- and further-line treatment (85\% of the cases). The baseline characteristics of the patients were similar between the carboplatin plus oral etoposide and the carboplatine plus intravenous etoposide arms.

Therapeutic efficacy. The median follow-up was 41.5 months (95\% CI: $10-50.5$ months). A total of 21 patients (77.8\%) had succumbed to the disease at the time of the data cut-off and 26 patients experienced disease progression.

The median PFS was 3.27 months (95\% CI: 1.90-4.19) and the median OS was 8.06 months (95\% CI:4.06-12.36). No significant difference was found between the two groups (log-rank, $\mathrm{P}=0.84$ ). One complete and 5 partial responses were observed, adding up to an ORR of $18.5 \%$. Stable disease was reported in 4 patients (14.8\%) (data not shown).

The median OS was 5.2 months (95\% CI: 3.8-6.6) for the carboplatin plus oral etoposide group, compared to 6.1 months (95\% CI: 2.0-10.3) in the carboplatin plus intravenous etoposide group. No significant difference was found between the two groups (log-rank, $\mathrm{P}=0.47$ ). In the univariate Cox analysis, none of the variables were found to be associated with OS (Table II). 
Table I. Patient characteristics.

\begin{tabular}{|c|c|c|c|c|}
\hline Characteristics & $\begin{array}{c}\text { All } \\
\text { patients } \\
(n=27)\end{array}$ & $\begin{array}{c}\text { Oral } \\
\text { etoposide } \\
(n=17)\end{array}$ & $\begin{array}{l}\text { Intravenous } \\
\text { etoposide } \\
(n=10)\end{array}$ & P-value \\
\hline Age, years [mean (range)] & $63.4(49-75)$ & $63.1(57.1-72.9)$ & $63.8(49.9-75.4)$ & 0.96 \\
\hline ECOG Performance status, n (\%) & & & & 0.55 \\
\hline $0-1$ & $23(85.2)$ & $14(82.4)$ & $9(90.0)$ & \\
\hline$>1$ & $4(14.8)$ & $3(17.6)$ & $1(10.0)$ & \\
\hline Gleason score, n (\%) & & & & 0.28 \\
\hline $6-7$ & $10(37.0)$ & $5(50.0)$ & $5(29.4)$ & \\
\hline $8-10$ & $17(63.0)$ & $5(50.0)$ & $12(70.6)$ & \\
\hline PSA, ng/ml [median (range)] & $104(0.23-2,471)$ & $172(0.23-2,471)$ & $51(1.15-504)$ & 0.18 \\
\hline $\begin{array}{l}\text { Previous hormone } \\
\text { therapy regimens, n }(\%)\end{array}$ & & & & 0.55 \\
\hline 1 & $17(63.0)$ & $10(58.8)$ & $7(70.0)$ & \\
\hline 2 & $10(37.0)$ & $7(41.2)$ & $3(30.0)$ & \\
\hline Previous chemotherapy, n (\%) & & & & 0.07 \\
\hline 0 & $4(14.8)$ & $2(11.8)$ & $2(20.0)$ & \\
\hline 1 & $12(44.5)$ & $5(29.4)$ & $7(70.0)$ & \\
\hline 2 & $6(22.2)$ & $5(29.4)$ & $1(10.0)$ & \\
\hline 3 & $4(14.8)$ & $4(23.5)$ & $0(0.0)$ & \\
\hline 4 & $1(3.7)$ & $1(5.9)$ & $0(0.0$ & \\
\hline Metastatic sites, n (\%) & & & & 0.21 \\
\hline Bone & $25(92.6)$ & $16(94.1)$ & $9(90.0)$ & \\
\hline Lymph nodes & $12(44.4)$ & $10(58.8)$ & $2(20.0)$ & \\
\hline Liver & $4(14.8)$ & $2(11.8)$ & $2(20.0)$ & \\
\hline Lung & $3(11.1)$ & $2(11.8)$ & $1(10.0)$ & \\
\hline Other viscera & $7(26.0)$ & $3(17.6)$ & $3(30.0)$ & \\
\hline
\end{tabular}

ECOG, Eastern Cooperative Oncology Group; PSA, prostate-specific antigen.

Compliance. Dose reduction was required in $78 \%(21 / 27)$ of the patients. Chemotherapy was interrupted in 3 cases $(11 \%)$ due to toxicity. No treatment-related deaths were reported. The dose intensity was $77 \%$ for oral etoposide and $80 \%$ for intravenous etoposide $(\mathrm{P}=0.57)$.

Adverse effects. The adverse events are presented in Table III. Grade 3-4 adverse events were observed in 14 patients (52\%). The most common grade 3-4 haematological toxicities were anemia, neutropenia and thrombocytopenia, in 9 (33.3\%), $7(25.9 \%)$ and $6(22.2 \%)$ patients, respectively. The most common non-hematological grade 3-4 toxicity was asthenia in $6(22.2 \%)$ patients.

The safety profile was generally similar between the oral etoposide and intravenous etoposide groups (Table II).

\section{Discussion}

This retrospective analysis assessed the efficacy and tolerability of the combination of carboplatin and etoposide in heavily pretreated $\mathrm{mCRPC}$ patients. In a phase II study by Loriot et al (7), 40 patients, following failure of standard treatment with docetaxel, received a median of 3 cycles of a combination of carboplatin $(\mathrm{AUC}=5)$ on day 1 and intravenous etoposide ( $80 \mathrm{mg} / \mathrm{m}^{2} /$ day) for 3 consecutive days. The median PFS and OS were 2.1 and 19 months, respectively. The majority of grade 3-4 toxicities were haematological (38\% neutropenia and $25 \%$ anemia). No thrombocytopenia was observed.

In a phase II study by Fléchon et al (8), 55 patients received a median of 4 cycles of carboplatin $(\mathrm{AUC}=4)$ on day 1 and intravenous etoposide $\left(100 \mathrm{mg} / \mathrm{m}^{2} / \mathrm{day}\right)$ for 3 consecutive days. The median PFS and OS were 2.9 and 9.6 months, respectively. The majority of grade 3-4 toxicities were haematological $(65.5 \%$ neutropenia, $32.7 \%$ thrombocytopenia and $27.3 \%$ anemia). In our study, the median PFS was 3.3 months and the median OS 8.1 months. The majority of grade 3-4 toxicities were also haematological (33.3\% anemia, $25.9 \%$ neutropenia and $22.2 \%$ thrombocytopenia). In the study of Loriot et al (7), only $10 \%$ of the patients had visceral disease and the patients were treated by carboplatin-etoposide after only one cycle of first-line docetaxel-based chemotherapy, which may explain the prolonged OS (19 months).

Poorly differentiated neuroendocrine prostate cancer (small-cell carcinoma, initially referred to as 'anaplastic') is 
Table II. Cox univariate analysis for overall survival.

\begin{tabular}{|c|c|c|c|}
\hline Variables & Median (95\% CI) & Log-rank P-value & $\begin{array}{c}\text { Univariate Cox analysis } \\
\text { HR }(95 \% \mathrm{CI})\end{array}$ \\
\hline Age, years & & 0.88 & \\
\hline$<63$ & $10.22(3.63-14.59)$ & & 1 \\
\hline$\geq 63$ & $7.93(3.70-14.98)$ & & $0.93(0.39-2.21)$ \\
\hline ECOG performance status & & 0.88 & \\
\hline $0-1$ & $7.80(4.06-12.36)$ & & 1 \\
\hline$>1$ & $8.72(3.63-14.98)$ & & $1.07(0.41-2.81)$ \\
\hline Gleason score & & 0.17 & \\
\hline $6-7$ & $3.88(1.54-14.59)$ & & 1 \\
\hline $8-10$ & $8.72(4.29-14.98)$ & & $0.53(0.21-1.33)$ \\
\hline PSA, ng/ml & & 0.31 & \\
\hline$\leq 104$ & 7.80 (2.0-NR) & & 1 \\
\hline$>104$ & $8.06(4.00-12.36)$ & & $1.58(0.64-3.89)$ \\
\hline $\begin{array}{l}\text { No. of previous hormone } \\
\text { therapy regimens }\end{array}$ & & 0.73 & \\
\hline 1 & $8.06(3.70-12.36)$ & & 1 \\
\hline 2 & 6.85 (3.14-NR) & & $0.85(0.34-2.13)$ \\
\hline No. of previous chemotherapies & & 0.52 & \\
\hline $0-1$ & $8.72(3.14-42.36)$ & & 1 \\
\hline$>1$ & $7.80(4.0-12.36)$ & & $1.33(0.54-3.29)$ \\
\hline Metastatic sites & & 0.94 & \\
\hline Bone \pm visceral/lymph node & $8.06(4.0-12.36)$ & & 1 \\
\hline Bone only & $8.47(2.0-14.98)$ & & $1.18(0.49-2.81)$ \\
\hline Chemotherapy regimen & & 0.47 & \\
\hline Oral etoposide & $5.2(3.8-6.6)$ & & 1 \\
\hline Intravenous etoposide & $6.1(2.0-10.3)$ & & $0.70(0.28-1.85)$ \\
\hline
\end{tabular}

CI, confidence interval; HR, hazard ratio; ECOG, Eastern Cooperative Oncology Group; PSA, prostate-specific antigen; NR, not reached.

Table III. Treatment-related toxicity.

\begin{tabular}{|c|c|c|c|c|}
\hline Adverse events & $\begin{array}{l}\text { All patients } \\
\qquad(\mathrm{n}=27)\end{array}$ & $\begin{array}{l}\text { Oral etoposide } \\
\qquad(n=17)\end{array}$ & $\begin{array}{l}\text { Intravenous etoposide } \\
\qquad(\mathrm{n}=10)\end{array}$ & P-value \\
\hline Anemia, n $(\%)$ & $9(33.3)$ & $5(29.4)$ & $4(40.0)$ & 0.45 \\
\hline Thrombocytopenia, n (\%) & $6(22.2)$ & $3(17.6)$ & $3(30.0)$ & 0.46 \\
\hline Neutropenia, n (\%) & $7(25.9)$ & $3(17.6)$ & $3(30.0)$ & 0.46 \\
\hline Febrile neutropenia, n (\%) & $1(3.7)$ & 0 & $1(10.0)$ & 0.15 \\
\hline Asthenia, n (\%) & $6(22.2)$ & $2(11.8)$ & $4(40.0)$ & 0.09 \\
\hline
\end{tabular}

a frequently under-recognized late manifestation of prostate cancer. Recognizing this subtype, which is considered to be a mCRPC, may be challenging. On the basis of autopsy series and other studies, neuroendocrine prostate cancer may represent $\sim 25 \%$ of late-stage prostate cancers (12). The diagnosis of neuroendocrine cancer is associated with clinical features not considered characteristic of prostate cancer, such as visceral involvement, lytic bone metastases and low or undetectable PSA levels; this subtype is also associated with a castration-resistant profile. Loriot et al (7) included patients who had mCPRC and in whom standard treatment with first-line docetaxel had failed. In the Fléchon et al (8) study, the patients had $\mathrm{mCRPC}$ with anaplastic characteristics, as defined by $\geq 1$ of the following criteria at trial entry: Visceral metastases (lung, liver, or lymph node involvement, excluding bone metastases) or elevated neuroendocrine marker serum 
levels (neuron-specific enolase and/or chromogranin A). In 2013, Aparicio et al (13) defined neuroendocrine prostate cancer as having 1 of 7 clinically assessable conditions, i.e., histological evidence of small-cell prostate carcinoma (pure or mixed), presence of visceral metastases alone, predominance of lytic bone metastases, bulky disease, inappropriately low PSA levels, neuroendocrine markers and a short interval to transition to an androgen-independent state. Therefore, a standardized definition of neuroendocrine prostate cancer is required.

Thiery-Vuillemin et al (9) demonstrated that the association of carboplatin (AUC $=5$ on day 1 ) and oral etoposide $(25 \mathrm{mg}$, 3 times daily) in 19 patients with varied solid tumors, 3 of whom had prostate cancer, reported an acceptable toxicity profile. In our study, efficacy, compliance and safety was generally similar between the oral etoposide and intravenous etoposide groups. The number of medical visits was less significant in the oral etoposide group, which, in this palliative setting, may significantly improve the quality of life.

Other regimens appear to show similar results to ours, including metronomic $40 \mathrm{mg}$ vinorelbine, with a median PFS of 4 months (33.0\%; 95\% CI: 15.6-55.3) (14). With eribulin, the median PFS was 1.9 months (95\% CI: 0.03-9.9) and the median OS 20.8 months (95\% CI: 2.2-32.4) (15). The combination of carboplatin-etoposide appears to be superior to other regimens, such as trabectedin (median PFS 1.5 months; 95\% CI: 0.9-1.8) (16). With metronomic oral cyclophosphamide, the median PFS was 5 months (95\% CI: 3-8) and the median OS 19 months (95\% CI: 8-28) (17).

OS and PFS have significantly improved with the novel agents, particularly enzalutamide. In the AFFIRM study, enzalutamide significantly improved OS compared with placebo $(\mathrm{HR}=0.63 ; 95 \% \mathrm{CI}: 0.53-0.75)(18)$, which suggests that conventional chemotherapies have their indications increasingly restricted, excluding docetaxel. Moreover, targeted therapy, such as cabozantinib, a novel experimental inhibitor of MET and vascular endothelial growth factor receptor 2, may be particularly effective in heavily pretreated patients with mCPRC. Cabozantinib achieved regression in $72 \%$ of patients with soft tissue lesions and an improvement in the bone scan in $68 \%$ of evaluable patients in a prospective study cohort including $171 \mathrm{mCRPC}$ patients. These results prompted the initiation of two phase III trials on cabozantinib (19).

In conclusion, in certain histological types, including neuroendocrine carcinoma, aggressiveness and lack of targeted therapies may be an indication for etoposide and carboplatin combination treatment, with close follow-up for potential complications. However, further investigations are required to determine the potential efficacy of this regimen.

\section{References}

1. Jemal A, Bray F, Center MM, Ferlay J, Ward E and Forman D: Global cancer statistics. CA Cancer J Clin 61: 69-90, 2011.

2. Huss WJ, Gregory CW and Smith GJ: Neuroendocrine cell differentiation in the CWR22 human prostate cancer xenograft: Association with tumor cell proliferation prior to recurrence. Prostate 60: 91-97, 2004.
3. Jin RJ, Wang Y, Masumori N, et al: NE-10 neuroendocrine cancer promotes the LNCaP xenograft growth in castrated mice. Cancer Res 64: 5489-5495, 2004.

4. Di Sant'Agnese PA and Cockett AT: Neuroendocrine differentiation in prostatic malignancy. Cancer 78: 357-361, 1996.

5. Helpap B, Köllermann J and Oehler U: Neuroendocrine differentiation in prostatic carcinomas: Histogenesis, biology, clinical relevance and future therapeutical perspectives. Urol Int 62: 133-138, 1999.

6. Arriagada R, Bergman B, Dunant A, Le Chevalier T, Pignon JP and Vansteenkiste $\mathrm{J}$; International Adjuvant Lung Cancer Trial Collaborative Group: Cisplatin-based adjuvant chemotherapy in patients with completely resected non-small-cell lung cancer. N Engl J Med 350: 351-360, 2004.

7. Loriot Y, Massard C, Gross-Goupil M, et al: Combining carboplatin and etoposide in docetaxel-pretreated patients with castration-resistant prostate cancer: A prospective study evaluating also neuroendocrine features. Ann Oncol 20: 703-708, 2009.

8. Fléchon A, Pouessel D, Ferlay C, et al: Phase II study of carboplatin and etoposide in patients with anaplastic progressive metastatic castration-resistant prostate cancer (mCRPC) with or without neuroendocrine differentiation: Results of the French Genito-Urinary Tumor Group (GETUG) P01 trial. Ann Oncol 22: 2476-2481, 2011

9. Thiery-Vuillemin A, Dobi E, Nguyen T, et al: Duration: escalation study of oral etoposide with carboplatin in patients with varied solid tumors. Anticancer Drugs 21: 958-962, 2010.

10. Eisenhauer EA1, Therasse P, Bogaerts J, et al: New response evaluation criteria in solid tumours: revised RECIST guideline (version 1.1). Eur J Cancer 45: 228-247, 2009.

11. Scher HI, Halabi S, Tannock I, Morris M, Sternberg CN, Carducci MA, et al: Design and end points of clinical trials for patients with progressive prostate cancer and castrate levels of testosterone: recommendations of the Prostate Cancer Clinical Trials Working Group. J Clin Oncol 26: 1148-1159, 2008.

12. Aparicio A, Logothetis CJ and Maity SN: Understanding the lethal variant of prostate cancer: Power of examining extremes. Cancer Discov 1: 466-468, 2011.

13. Aparicio AM, Harzstark AL, Corn PG, et al: Platinum-based chemotherapy for variant castrate-resistant prostate cancer. Clin Cancer Res 19: 3621-3630, 2013.

14. Briasoulis E, Aravantinos G, Kouvatseas G, et al: Dose selection trial of metronomic oral vinorelbine monotherapy in patients with metastatic cancer: A Hellenic Cooperative Oncology Group clinical translational study. BMC Cancer 13: 263, 2013.

15. De Bono JS, Molife LR, Sonpavde G, et al: Phase II study of eribulin mesylate (E7389) in patients with metastatic castration-resistant prostate cancer stratified by prior taxane therapy. Ann Oncol 23: 1241-1249, 2012.

16. Michaelson MD, Bellmunt J, Hudes GR, et al: Multicenter phase II study of trabectedin in patients with metastatic castration-resistant prostate cancer. Ann Oncol 23: 1234-1240, 2012.

17. Yashi M, Nishihara D, Mizuno T, et al: Metronomic oral cyclophosphamide chemotherapy possibly contributes to stabilization of disease in patients with metastatic castration-resistant prostate cancer: A prospective analysis of consecutive cases. Clin Genitourin Cancer 12: e197-e203, 2014.

18. Scher HI, Fizazi K, Saad F, et al; AFFIRM Investigators: Increased survival with enzalutamide in prostate cancer after chemotherapy. N Engl J Med 367: 1187-1197, 2012.

19. Smith DC, Smith MR, Sweeney C, et al: Cabozantinib in patients with advanced prostate cancer: Results of a phase II randomized discontinuation trial. J Clin Oncol 31: 412-419, 2013. 